\title{
Autosomal dominant neovascular inflammatory vitreoretinopathy
}

INSERM

\section{Source}

INSERM. (1999). Orphanet: an online rare disease and orphan drug data base. Autosomal dominant neovascular inflammatory vitreoretinopathy. ORPHA:329211

Autosomal dominant neovascular inflammatory vitreoretinopathy is a rare, genetic, vitreoretinal degeneration characterized by a slowly progressive vitreoretinopathy with onset during the second or third decade of life. The disease initially presents as autoimmune uveitis with reduction in the b-wave on electroretinography, and progresses with development of photoreceptor degeneration, vitreous hemorrhage, cystoid macular edema, retinal neovascularization, intraocular fibrosis, secondary glaucoma, and retinal detachment leading to phthisis and complete blindness. 